\title{
Privatizing State-Owned Enterprises
}

\begin{abstract}
This chapter describes the formulas for privatization that were used to privatize almost all state-owned assets in Georgia between 2004 and 2011, including its ports, airports, water utilities, and power grid. To improve service levels and ensure long-term economic feasibility for investors, the government followed a best-practice process, comprising five steps - from replacing top managers and laying down the regulatory framework for the future private companies to screening and selecting bidders. The chapter also explains why Georgia's railway and its oil and gas corporation were exempt from full privatization. It concludes with a discussion of alternatives to outright privatization, such as issuing Eurobonds and establishing public-private partnership funds, which combine the benefits of competitive pressure on public enterprises with governmental control.
\end{abstract}

Keywords Railway - State-owned-enterprises - London stock exchange $(\mathrm{LSE}) \cdot \mathrm{IPO} \cdot$ Partnership fund $(\mathrm{PF}) \cdot$ Public Private Partnership (PPP)

Between 2004 and 2011, Georgia privatized almost all state-owned assets, including its ports, airports, water utilities, and power grid. To improve service levels, protect the long-term interests of the state, and

(C) The Author(s) 2017

N. Gilauri, Practical Economics,

DOI 10.1007/978-3-319-45769-7_6 
ensure sufficiently attractive returns for investors, the government followed a five-step process:

1. Step one was to replace top management with new or interim managers, since incumbent directors showed little interest in successful privatization.

2. Step two was to restructure state-owned enterprises, in particular to lay off those employees who had been hired for the wrong reasons. This step was both painful and unpopular, but inevitable, since even the smallest inefficiency would have increased the bargaining power of potential investors.

3. Step three was to lay down the regulatory framework for the future private companies, e.g., their suppliers, customers, and mid-term obligations.

4. Step four was to draft tender documents and privatization agreements.

5. Step five was to screen and select bidders in an open auction.

Only Georgia's railway and its oil and gas corporation were exempt from privatization for geopolitical reasons. These assets remain under public control, but the government has taken innovative steps to improve their performance.

\subsection{The Challenge}

State-owned enterprises (SOEs) everywhere are a hotbed for inefficiency, and Georgia was no exception. In the early 2000s, corruption was the norm at its SOEs. Politicians treated SOEs as their personal cash cows, and most decisions were driven by greed, rather than by an interest to promote the greater good of the country as a whole. For example, members of government routinely appointed people to leadership positions at SOEs in return for handouts or other favors. This is what it's like in many other countries, be they developed or developing, even today. Unless the government takes special precautions, SOEs invariably veer toward inefficiency and corruption. The root cause of this tendency is the fact that the state, as the owner, has little inherent interest in maximizing the profit of an SOE. There are plenty of other sources of budgetary income, such as taxes and customs, and the resources of SOEs can be used in many ways other than to maximize net profit: to finance politically sensitive projects and hide them from parliamentary review, to secure the favor of voters 
prior to an election, or simply to find employment for friends and family. That's what things were like in Georgia before 2004.

Whenever calls for privatization arise, politicians routinely deploy heavy rhetorical artillery: the state should hold on to its assets and keep strategic companies under public control. Foreign companies should not be allowed to take over, or even manage, any "national treasures." Such populist appeals to pride and nationalism resonate well with many people, especially in small developing countries. In reality, most politicians who make this sort of declaration are only trying to protect their jobs or their illicit income.

So how should utility, energy, and transport be managed in a modern democracy? Is privatization the only option to prevent corruption and increase efficiency? Are certain types of state-owned companies better suited to privatization than others? Which assets, if any, should be exempt from privatization?

The lesson we learned in Georgia, and elsewhere, is that privatization is a double-edged sword. If you handle it well, it is a powerful tool that will make the state stronger and bring benefit to the population. If, however, it is handled unprofessionally, let alone in a corrupt manner, it will inflict harm on the state and bring disadvantage to its citizens. In any case, stateowned enterprises should be restructured prior to privatization, and proper regulation should be put in place to make sure future owners of SOEs don't exploit their position as de facto monopolists at the expense of the public. As a general rule, at least two investors should be shortlisted for any privatization effort to ensure some measure of competition. SOEs from other countries should not normally be admitted as investors to take over an SOE. One SOE buying up another SOE doesn't really qualify as privatization, and it doesn't bring the full benefit from the perspective of the state. Even if future losses will be absorbed by another government, chances are that the new company will be no more efficient than its predecessor. Finally, governments should not hesitate to hire reputable consulting companies to help with the legal, financial, and transactional aspects of the privatization process, or even have contractors manage SOEs for a limited transitional period prior to privatization. All potential investors will be working with the best experts in their fields, and the least a responsible government can do is make sure it is on an equal footing with bidders in this respect. Negotiating a well-structured, profitable deal is no small matter. It goes beyond the expertise of even the finest public servants, which is why the fees of experts will easily pay for themselves. 
In Georgia, we followed a five-step privatization process, and it served us well. I recommend that other countries take inspiration from it and adapt it to their needs.

\subsection{The Five-Step Process}

Step $I$ is to replace the CEO and directors of the company. Nobody likes to kill their darlings, and if you have managed a company for years, or even decades, that company inevitably will have become your darling. You will feel that you have given it your all, and that your team has done the best it could - the best, in fact, anybody could have done under the circumstances. From the perspective of a veteran, bringing in new managers will look like a waste of resources. Nine out of ten times, an incumbent CEO will not support the privatization process. Leaving an SOE's top team in place prior to privatization is the biggest mistake governments can make. The old guard will often not disclose relevant information to potential investors they don't approve of, at least not fully and truthfully, and they will impair the impact of privatization by striking shady deals with the future owners of the SOE to keep their jobs. The mission of an incoming CEO and top team should be very clear: ensure successful privatization, period. Typically, this is a temporary rather than a permanent assignment, and the government should be clear about this from the start. The objective for the new management is to restructure the company and sell it. Ideally, remuneration is tied to the total value created through the privatization contract, including the price of the sale and any investment obligations imposed on the new owner.

Step 2 is to restructure the company. Almost all SOEs are inefficient in one way or another. Common issues include:

- Employees hired solely as a favor to politicians

- Managers promoted to positions of leadership based on tenure or political affiliation, rather than qualification or performance

- Onerous contracts causing the SOE incessant losses

To fix these issues, you need political consensus that the company is to be privatized, and that the government should take the appropriate measures to find a high-caliber investor, get the best possible price, and secure the 
commitment of the prospective new owner to invest in the company in future. To achieve these objectives, the company must be as lean and efficient as possible prior to privatization - lay off employees who are not needed, replace managers who are not qualified for their positions, and renegotiate or terminate unfavorable contracts. It is a common, but costly, mistake to leave these issues to the new owners. The fact is that every little inefficiency of an SOE gives undue bargaining power to potential investors during negotiations and will decrease the total value of the privatization contract.

Step 3 is to set up a proper regulatory framework. It should cover the following questions: Are the processes required to ensure proper checks and balances already in place? Or will it be very difficult for the government to understand what is going on in the sector in question after privatization? Specifically, is a proper reporting requirement in place to keep the government in the loop? What is the structure of the tariff system? Is it sufficiently attractive to attract reputable companies as investors and ensure they resist the temptation of making money on the side? Is there any danger of the new owner exploiting the monopolistic position of the company? If yes, which precautions are required to minimize the risk of the new owner besting the state or its customers? Rules and regulations for the sector in question must be clear and transparent to all parties to enable them to take fact-based, wellinformed decisions.

Step 4 is to prepare the tender documents and draft the actual privatization agreement, ideally with the help of well-established international consultants. The contract should not only specify the terms and conditions of the deal itself, but also spell out the investment obligations of the future owner for the next five to seven years. The deal should be structured in a way that balances multiple objectives:

- Provide an attractive investment opportunity for the bidder

- Attract investment to the company and make it more efficient

- Help the rest of the economy become more competitive

- Secure better service in the sector in question

- Maximize total long-term value creation for the state

Step 5 is the actual selection process. This should start with a roadshow and advertisements as required to attract the best players in the sector or industry 
in question. An open auction should be held with the most suitable bidders. For details on auctions, also see the chapter on Fighting Corruption.

Typically, the right to participate in the first round of negotiations will go to the bidder offering the highest price. The highest sale price, however, will not always be the best deal. From the perspective of the state, value creation can take many different shapes. More efficient operations, better management, transfer of know-how, and future investment obligations can easily compensate for a slightly lower sale price. In any case, the contract should protect the long-term interests of the state and allow the investor to make a good, clean profit in the medium term. That is why it is very important to define and communicate the selection criteria and their weighting upfront: Will the final decision be taken based on price alone? Will obligations regarding future investments play a role? What about management experience and technical expertise? Personally, I have found that it is best to use only criteria that can be quantified in the last tender and to create a clear-cut formula as to how they will factor in the decision. Qualitative criteria, such as an experienced management team, should only be used in the initial screening stage. In other words, bidders who do not fulfill these criteria should not even be admitted to the final round. And once a bidder is admitted to the final round, qualitative criteria should not be applied again, assuming that all participants who have made it this far satisfy the government's qualitative requirements.

Regarding the final round itself, it is crucial to create a formula that all parties understand. This is exactly what we did when we put one of the utilities in Georgia out for tender. From the perspective of the government, it was crucial for the tariffs to stay as low as possible for as long as possible, and we made this clear to all potential investors. We also defined the investments the future owner of the utility would have to make over the course of the coming years. Based on these preconditions, we asked potential investors to submit proposals specifying tariff levels for the next seven years and the price they were willing to pay. The formula we would apply to select the winning proposal was predefined and clearly communicated to bidders: a specific weight was given to the tariff for every year, and these weights added up to account for 50 percent of the decision. The remaining 50 percent weight was attached to the price the bidder was willing to pay. Thanks to the transparent approach, this turned out to be one of the most efficient tenders we ever conducted. 


\subsection{The Outcome in Georgia}

Between 2004 and 2011, almost all state-owned assets in Georgia were successfully privatized based on the five-step process outlined previously. Examples include ports and airports, electricity and gas distribution companies, hydroelectric power plants, and water utility companies. These efforts were successful in several respects:

- Investors fulfilled the obligations imposed under the respective privatization contracts. Specifically, they invested substantial amounts of capital and transformed formerly troubled SOEs into financially sound private companies.

- The new companies grew in terms of efficiency and effectiveness.

- Consumers and corporate customers were happy with how the new companies performed and the services they provided.

- Investors were happy. They made sizable upfront investments, but now they are reaping the rewards in the form of substantial profits.

In 2005, for example, Tbilisi airport was privatized by way of a buildoperate-transfer (BOT) contract with TAV, a Turkish company that also operates the airports of Istanbul in Turkey, Skopje in Macedonia, Zagreb in Croatia, and in many other cities in the region. In 2007, Tbilisi airport was thoroughly renovated and expanded, tripling its annual passenger capacity. Today, the airport connects Georgia to various international destinations such as Rome, Paris, Moscow, Istanbul, Dubai, Frankfurt and others. In contrast, privatization efforts were less successful in those cases in which a Georgian SOE was taken over by an SOE from another country. The investments the foreign SOEs made were usually both insufficient and inefficient. Generally, the new companies did not receive the attention and the support they would have required.

But the vast majority of privatization efforts was successful. Our experience shows that privatized companies are more efficient than SOEs, and that they contribute to economic growth within and beyond their industries, more so than SOEs. Because private companies are profit-oriented and cannot rely on state subsidies, they are forced to innovate more, to attract better personnel, to develop better know-how, to invest more in $R \& D$, and to adopt superior management practices. And unlike most SOEs, they do not consume public funds. Instead, they contribute to the state's budget by paying taxes, and the proceeds of privatization itself can be invested by the 
government to develop new infrastructure. Generally, managers of privatized companies have a much bigger incentive to improve performance than the directors of SOEs, which is why all state-owned assets should be privatized - unless privatization brings undue geopolitical tension.

\subsection{Strategic Assets}

Since the dawn of capitalism, politicians and economists have debated the limits of privatization. Are there any companies that a government should never sell because of strategic considerations? For example, will the privatization of electricity distribution, electricity transmission, or railway operations put the country at a disadvantage in times of geopolitical turmoil? The experience in Georgia shows that there are, in fact, such strategic assets, and that the government should not sell them, at least not without taking proper precautions to protect the interests of the state. However, our experience also shows that the nature of such strategic assets differs from country to country. What is more, we also found that there is an attractive middle ground between state ownership and blunt privatization, and that some strategic assets can be considered for partial privatization, provided the underlying contract is well designed and regulation is appropriate to protect the interests of the state. In a nutshell: you can sell anything, or almost anything, if the contract and the regulation are watertight.

Examples of privatizing these so-called strategic assets and due to prudent regulations being still under control even during most difficult geopolitical situation, include privatization of Telasi, Tbilisi's electricity distribution company, and the partial divestment ( 50 percent share) of the transmission line connecting the Georgian and Russian energy grids. In both cases, although the investors were state-owned or state-controlled Russian companies, neither of these entities were used against Georgia's interests during the Russian invasion. The regulation that was put in place was well crafted and very straight forward and the management of the companies knew very well that in case it acted against the national interests of the government they would have been taken over (managerially not ownership wise) by the regulator. During the war, these companies followed closely instructions from the central dispatcher, and energy supply was neither interrupted nor impaired at any point. Thanks to good regulation, strategic assets remained under the government's control during this sensitive period.

Surely, experts in most countries would classify electricity distribution and the high-voltage power grid as highly sensitive and potentially 
vulnerable parts of a state's technical infrastructure. But if even these assets can be in the hands of a hostile foreign power during a war without harm coming to the country, which other assets, if any, should the government not privatize for strategic reasons? In Georgia's case, it was the Georgian Railway (GR) and the Georgian Oil and Gas Corporation (GOGC).

Because of tense political relations between two of Georgia's neighbors, Azerbaijan and Armenia, privatizing the GR and the GOGC could have turned into a geopolitical conflict, a conflict that would have been disastrous for the whole region and for Georgia itself. This is because almost all of Armenia's imports use the GR, and almost 100 percent of Armenia's gas consumption goes through the GOGC. Everybody agreed that political stability was much more important than any commercial benefit that might come from the privatization of these assets. The Georgian government decided to hold on to the GR and the GOGC, lest they be used as geopolitical weapons by an investor, a foreign power, or any other party.

In these cases, privatization was not an option. However, we still wanted to improve efficiency and introduce a certain performance culture at the GR and the GOGC. The solution we found was to have these companies issue corporate Eurobonds at the London Stock Exchange. The idea was to measure the performance of the top team, and reward it with bonuses, based on the difference between sovereign Eurobonds (issued by Georgia's national government) and corporate Eurobonds (issued by GR and the GOGC). ${ }^{1}$ In effect, we had the world's financial markets assess the performance of the respective management teams for us. High demand, and the resulting high valuation, of GR and GOGC bonds would signify that investors believed in the leadership teams and did not see major risks regarding the future performance of these companies. This step motivated the managers at GR and the GOGC to be transparent, seek close relations with investors, and to adopt best management practices. As a side effect - managers of these companies acted as best salespersons of the country itself - as most questions from investors were about the country's economic situation. All of this helped to advance the performance not only of these companies but also of Georgia's economy as a whole, and I believe that other developing countries would benefit in similar ways.

As mentioned previously - privatization can go wrong and hurt a country's economy for long term. In the Ukraine, for example, the privatization of state assets went wrong in a big way in the 1990s. It resulted in a situation in which a handful of oligarchs control most of these assets, a major obstacle to the country's growth. The oligarchs in Ukraine, in many cases, have their 
own political parties, control part of the media and control different parts of the government. They are primarily motivated by the desire to defend/ increase their wealth and fortify their political positions, not by any great urge to advance the prosperity of the country as a whole. Their interests do not coincide with the interests of the country and any positive initiative by one is accepted by others as a potential threat and is blocked.

In the autumn of 2015, I was invited to Kiev to present Georgian economic reforms to the Ukrainian government. After presenting the Georgian story to all stakeholders (members of government and IFIs, representatives of private sector and NGOs) I met with a Ukrainian minister of economy. As a way out of the predicament, I offered him an out-of-box solution that may have changed the country and create a stepping stone for the turnaround path of Ukrainian economy. The idea was to adopt a legislation that would oblige the oligarchs within specific a timeframe to take their companies to international financial markets (e.g., London Stock Exchange) to IPO (formula for privatization - Initial Public Offering). This may have been very much accepted by all oligarchs as all of them, being in the same situation, would have been calm that nobody is taking their assets from them (but they are maximizing their wealth on the international financial markets) and would force them to act in the best interests of the country - their successful IPOs and thus their wealth would depend on how well country is performing. On top, they would be forced to attract best managers with international experience in their companies, clean up the most important assets, and start paying taxes fully. The minister loved the idea. He shook my hand and said that he would do his best to take the proposal to the president and that he would come back to me. $\mathrm{He}$ never did. The government of the Ukraine, including the minister of economy, has since been succeeded by a new administration. It still remains to be seen if the new government will be up to thinking out of the box and adopt this or a similar regulation. Using existing experiences only may not be the best solution for particular problems. Innovative approaches to new problems are required in cases and the Ukrainian case, I believe, is one of them.

\subsection{PARTNERShip Funds}

Another tool to improve the performance of SOEs without privatizing them is to set up public-private partnership funds. The Georgian government established such a partnership fund in 2010 , set up as a holding entity that holds shares of large SOEs and uses dividend income, privatization proceeds, or bond proceeds to develop new infrastructure in cooperation with the 
private sector. The main objective was to assist international investors with the financing of large-scale infrastructure projects. Because of the relatively small size of Georgia's economy at the time, it was difficult to convince investors to shoulder the full risk of major infrastructure investments without public co-financing or state guarantees. Promising projects were stalled because investors felt the investment was too large relative to the size of the country's economy. These projects promised robust returns on investment, but they required investments exceeding 6 percent of Georgia's GDP, and investors would only consider these projects if the state would chip in with co-financing or back them up with guarantees.

The government, however, was unwilling to give outright guarantees. This was because the country had had negative experiences with such guarantees in the past. They had mostly been used to fill the coffers of corrupt individuals rather than to help develop the country's economy. So the partnership fund $(\mathrm{PF})$ was created. Its objective was to help the private sector with major investments in infrastructure that would benefit the country as a whole without having to grant governmental guarantees. The PF held shares of all major SOEs - such as GR, GOGC, and GSE ${ }^{2}$ - and was the financial beneficiary of these companies, but the PF was not to be involved in the day-to-day management of these SOEs. The primary role of the PF was to set dividend policies for these companies in cooperation with the Ministry of Finance and other relevant ministries. Additionally, the PF would invest in large-scale infrastructure projects in cooperation with the private sector.

Initially, it was anything but trivial to find the golden middle ground between a hands-off investment approach and a hands-on management approach. The private sector was concerned that the PF would act as their competitor. Which sectors would it get involved in? What, exactly, would its goal be? Turn a profit for the government? Create jobs? Bring consumer prices down? Would the PF have privileged access to foreign direct investment in a particular sector at the expense of private companies? How would the fund choose its partners - based on experience, on co-financing, or in exchange for bribes? All of these concerns brought uncertainty to the economy, at least initially. Yet we believed that it was worth the effort to hang in and resolve these issues. The PF was, quite simply, the only way to get big things built in a small economy like Georgia, where the construction of a single large Hydro Power Plant (HPP) would require an investment in the magnitude of 10 percent of the country's GDP.

To address the concerns of the private sector and hedge the risk of the investment, Georgia's PF was given very limited powers. The areas and 
specific projects in which the PF would invest were specified in advance. The fund was only to invest in projects of a certain size, and its cofinancing capacity was restricted to a maximum of 49 percent of equity. Also, the fund was obliged to sell its share in any project within four to five years to the private partner company or another investor. Additionally, a special supervisory board was established. It consisted of members of the government and representatives of the private sector, mainly of the banking sector. This was to prevent the PF from competing with private banks for suitable projects and from taking business away from them.

Unfortunately, the PF did not consult the board as actively as the government had originally envisaged. This created considerable unrest among private sector players. These drawbacks do not, however, discredit the concept of a state-owned financial vehicle tasked with helping private investors finance large infrastructure projects in developing countries. They merely illustrate that any such vehicle requires a clear definition of its role and duties by legislation, as well as meticulous management and oversight, to make sure it benefits both the public and the private sector.

\section{Notes}

1. http://www.investopedia.com/terms/s/sovereignbond.asp; http://www. investopedia.com/terms/c/corporatebond.asp (retrieved in May 2016).

2. Georgian Railway, Georgian Oil and Gas Corporation, and Georgian State Electrosystem.

Open Access This chapter is distributed under the terms of the Creative Commons Attribution 4.0 International License (http://creativecommons.org/licenses/by/4.0/), which permits use, duplication, adaptation, distribution and reproduction in any medium or format, as long as you give appropriate credit to the original author(s) and the source, provide a link to the Creative Commons license and indicate if changes were made.

The images or other third party material in this chapter are included in the work's Creative Commons license, unless indicated otherwise in the credit line; if such material is not included in the work's Creative Commons license and the respective action is not permitted by statutory regulation, users will need to obtain permission from the license holder to duplicate, adapt or reproduce the material.

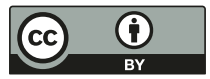

